\title{
OUTCOME OF CONSERVATIVE MANAGEMENT IN BILIARY ASCARIASIS - A STUDY OF 98 CASES
}

\author{
KHAN AS ${ }^{1}$, BHOWMIK B ${ }^{2}$, HAKIM HAN ${ }^{3}$, ISLAM MA ${ }^{4}$
}

\begin{abstract}
Objectives: History of ascariasis is very old. One quarter of the world's population is known to be infected by ascariasis. It is endemic in various parts of Bangladesh. We aimed to study the various types of clinical presentations, complications and different diagnostic tools and to assess various options for the management of biliary ascariasis.

Materials and Methods: Ninty eight cases of hepatobiliary ascariasis were studied over a period of 2 years (April 03 - April 05). All the patients were aged between 12 and 73 years and all were admitted with acute right upper abdominal pain. Ultrasound was the diagnostic tool of choice with $100 \%$ results.

Results: In this study, biliary ascariasis was found to be more common in females $64.29 \%$ (64 patients). The most common presentation was upper abdominal pain in 100\% of the patients (98 patients). Complications observed were obstructive jaundice in 08.16\% (8 patients), cholangitis in $74.49 \%$ (73 patients). History of worm emesis was present in $21.42 \%$ (21 patients). Conservative management was successful in 96.94\% (95 patients). During follow-up, worm reinvasion of the biliary system occurred in $7.1 \%$ (three patients).
\end{abstract}

Conclusion: In endemic countries, biliary ascariasis should be suspected in patients with biliary disease. Most of the patients respond to conservative management.

Keywords: Acute upper abdominal pain, biliary ascariasis, Ultrasonography

J Dhaka Med Coll. 2010; 19(1) : 25-28.

\section{Introduction}

1. Ascaris lumbricoides, a nematode, is the causative agent of ascariasis. It is the most common helminthic infestation in the world. It is prevalent mainly in the developing countries.It usually affects people from the lower socioeconomic groups living in unhygienic conditions.

The adult round worm normally lives in the small intestine. Because they have desire to travel and tend to explore ducts and cavities ${ }^{1}$. They often invade the bile or pancreatic ducts. After cholelithiasis, it is the second most common cause of acute biliary symptoms worldwide. All the patients in this study presented in the emergency department with acute upper abdominal colicky pain. In endemic areas, biliary ascariasis is frequently found and should be kept in mind as an important cause of acute upper abdominal pain.

\section{Materials and Methods}

A total of 98 patients (63 females and 35 males) with biliary ascariasis were studied over a period of 2 years in the Sher-e-Bangla Medical College and Hospital, Barisal, Bangladesh. All were aged between 12 and 73 years belonging to various parts of Barisal division.

Clinical assessment was performed in all the cases. History of passage of worms in the stool or vomitus and recurrent abdominal pain, with or without jaundice, was taken in each case. Previous history of surgery or endoscopy to the gastrointestinal tract was noted. Complete blood cell count, liver function test, serum amylase, $\mathrm{X}$-ray of the chest and abdomen and ultrasound of the abdomen was performed in all the patients at the time of admission and repeated when required. The mainstay of the diagnostic tool was ultrasound of the abdomen.

All the patients were initially managed conservatively with IV fluids, IV antibiotics and

1. Resident Surgeon (General), DMCH, Dhaka

2. Radiologist, DMCH., Dhaka

3 Resident Surgeon (Casualty), DMCH, Dhaka

4. Associate Professor, Department of Surgery, Sher-e-Bangla Medical College, Barisal

Correspondence: Dr. AS Khan 
IV antispasmodics and nothing per oral. All the patients were dewormed with repeated dose of $400 \mathrm{mg}$ of albendazole, $500 \mathrm{mg}$ of mebendazole. Surgical intervention was carried out when conservative treatment failed. Serial ultrasonography was performed to check for recurrence during follow-up. The patients were dewormed at 3-monthly intervals.

\section{Results:}

In this study, Biliary ascariasis was found common among the younger age group. About $69.38 \%$ cases are within 10-30 yrs of ages, youngest one being 12 yrs old boy and oldest one is 73 yrs old woman[Table-I]. Biliary ascariasis was found to be more common in females (64.29\%)[Table-II]. The most common presentation was upper abdominal pain in $100 \%$ of the patients. The clinical symptoms and signs are given in [Table-III].

Table-I

Age distribution (N-98)

\begin{tabular}{lcc}
\hline Age in yr & No. of patients & Percentage \\
\hline $10-20$ & 33 & 33.67 \\
$21-30$ & 35 & 35.71 \\
$31-40$ & 15 & 15.31 \\
$41-50$ & 8 & 8.16 \\
$51-60$ & 4 & 4.08 \\
$61-70$ & 2 & 2.04 \\
$71-80$ & 1 & 1.02 \\
\hline
\end{tabular}

Table-II

sex distribution in biliary ascariasis ( $N-98)$

\begin{tabular}{lcc}
\hline Sex & No. of patients & Percentage \\
\hline Female & 63 & 64.29 \\
Male & 35 & 35.71 \\
\hline
\end{tabular}

Table-III

Clinical presentation of biliary ascariasis (N-98)

\begin{tabular}{|c|c|c|}
\hline Symptoms & No. of patients & Percentage \\
\hline $\begin{array}{l}\text { Pain in rt } \\
\text { hypochondrium }\end{array}$ & 98 & 100 \\
\hline Nausea & 83 & 84.69 \\
\hline Vomiting & 41 & 41.84 \\
\hline Fever & 73 & 74.49 \\
\hline Rigor & 13 & 13.26 \\
\hline Jaundice & 08 & 08.16 \\
\hline Worm emesis & 21 & 21.42 \\
\hline
\end{tabular}

About $96.94 \%$ of the patients responded to conservative therapy [Table-IV]. Most of the patients responded to this treatment in 4-5 days. In some patients, the above treatment had to be continued up to 14 days. Patients were monitored by serial ultrasound to know the status of the worms in the biliary tree. Surgery was performed in three cases. The indications were retention of dead worms in the common bile duct with obstructive jaundice. Cholecystectomy with common bile duct exploration was carried out. Common bile duct exploration revealed dead round worm along with choledocholithiasis.

\section{Table-IV}

Treatment protocol for biliary ascariasis $(N-98)$

\begin{tabular}{lcc}
\hline Protocol & No. of patients & Percentage \\
\hline Conservative & 95 & 96.94 \\
Operative & 03 & 03.06 \\
\hline
\end{tabular}

Patients were followed-up for 6 months with serial ultrasonography. Worm reinvasion was not detected during this period.

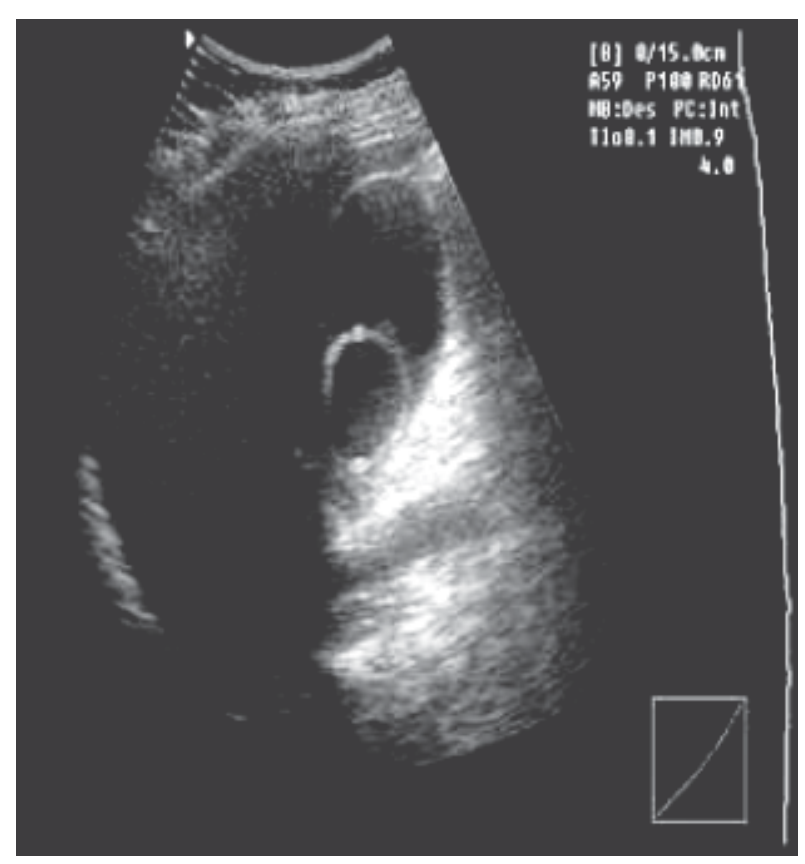

Fig.1 : Round Worm in Gall Bladder 


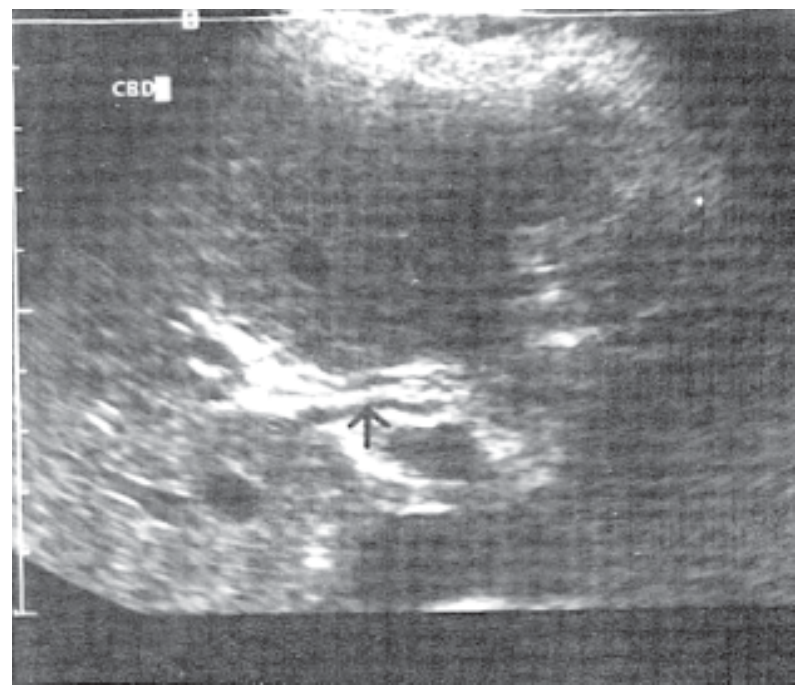

Fig.-2 : Ascaris in $C B D$

\section{Discussion:}

Biliary ascariasis is commonly reported from highly endemic regions like Bangladesh, India, Latin America, parts of the Middle East and Africa. In humans, the usual habitat of $A$. lumbricoides is the small intestine. When the worm load is high, which may go up to a 1000 worms, the worms tend to migrate away from the usual site.

Symptoms of biliary colic occur when the worm migrates across the papilla. If the worm remains in the bile duct [Fig.-2] and gall bladder [Fig.-1], acute and chronic complications can occur, like cholangitis, strictures, calculi, cholecystitis and pancreatitis. ${ }^{[3]}$ Some worms may travel up and colonize in the liver parenchyma forming liver abscess ${ }^{4}$.

Women are more commonly affected than men. Recurrent worm invasion of the ducts has also been frequently observed in endemic regions.

The diagnosis of biliary ascariasis usually depends on the demonstration of worms in the biliary tract by different imaging techniques. Sonography has been shown to have a high diagnostic accuracy as a noninvasive procedure in the diagnosis of biliary ascariasis.

[10] Various appearances of round worms in the biliary tract and gall bladder have been described. [10],[11] They are as follows:

1. Inner tube sign - The round worm may be seen as a thick echogenic stripe with a central anechoic tube (gastrointestinal tract of the worms) in the gall bladder or common bile duct.

2. Stripe sign - Thin nonshadowing stripe without an inner tube within the gall bladder or common bile duct.

3. Spaghettli sign - Overlapping longitudinal interfaces in the main bile duct due to coiling of a single worm or several worms in the common bile duct.

In addition, real time sonography may demonstrate mobility of the worms within the gall bladder and biliary passages thus equivocally establishing the diagnosis. Ultrasonography is also helpful in monitoring the exit of the worms from the biliary tract.

Endoscopic retrograde cholangio pancreatography (ERCP) usually shows the worm as a long filling defect. Successful extraction of the worm from the common bile duct via endoscope has been reported in the literature. ${ }^{[12],[13],[14]}$ But, the use of ERCP must be balanced against potential complications of the procedure. Moreover, sphincterotomy performed during ERCP for worm extraction predisposes to recurrent worm infestation. Because this disease is more rampant in the poorer tropical countries of the world, the expense of an ERCP adds significantly to the overall cost of treatment. This holds true for Bangladesh. Therefore, ERCP as a therapeutic intervention should be considered if a patient fails to respond to conservative treatment or the worm persists (serial sonograms) or has died within the pancreaticobiliary tree. [15] Presence of coexistent strictures or stones within the ducts is also an indication.

More than $95 \%$ of the patients with uncomplicated biliary ascariasis will respond to conservative management, the worms returning spontaneously to the intestine. [3],[4] In a study from Kashmir, conservative management was successful in $88 \%$ of the patients. [16]

\section{Conclusion:}

In Bangladesh, biliary ascariasis is a frequent diagnosis in patients presenting with symptoms of biliary colic. Most of the patients of biliary ascariasis respond to conservative 
treatment. Ultrasonography of the abdomen has been advocated as a quick, safe, noninvasive and relatively inexpensive modality with a high diagnostic accuracy for suspected biliary ascariasis.

\section{References:}

1. Langewar DN, Maheshwari MB, Wegholikar UL. Hepatic perforation due to ascariasis. Indian $\mathrm{J}$ Pediatr 1993;60:457-9.

2. Mani S, Merchant H, Sachdev R, Rananavare R, Cunha N. Sonographic evaluation of biliary ascariasis. Australas Radiol 1997;41:204-6.

3. Louw JH. Biliaray ascariasis in childhood. S Afr J Surg 1974;12:19-25.

4. Lloyd DA. Massive hepatobiliary ascariasis in childhood. Br J Surg 1981;68:468-73.

5. Braga LH, Tatsuo ES, Guimaryes JT, Miranda ME, Paixyo RM, Teixeira CR, et al . Biliary ascariasis after Roux -en-Y hepaticojejusnostomy. J Pediatr Surg 2000; 35: 1394-5

6. Bude RO, Bowerman RA. Biliary ascariasis. Radiology 2000;214:844-7.

7. Gonzalez AH, Regaldo VC, Van den Ende JV. Noninvasive management of Ascaris lumbricoides biliary tract migration: A prospective study in 69 patients from Ecuador. Trop Med Int Health 2001;6:146-50.

8. Schulman A, Loxton AJ, Hegdenrych JJ, Abdulrahaman KE. Sonographic diagnosis of biliary ascariasis. AJR. 1982;139:485-9

9. Cerri GG, Leite GJ, Simoes JB, Correia Da Rocha DJ, Albuquerque FP, Machado MC et al. Ultrasonographic evaluation of Ascaris in the biliary tract. Radiology 1983;146:753-4.

10. Jessen K, Al Mofleh, Al Moferrah M. Endoscopic treatment of ascariasis causing acute obstructive cholangitis. Hepatogastroenterology 1986;33:2757

11. Jamsheer NS, Malik N, Al-Qamish J. Biliary ascariasis: Sonographic diagnosis. Saudi J Gastroenterol 2001;7:69-70.

12. A1-Karawi MA, Salem I, Mohammed AS. Endoscopic diagnosis and extraction of biliary ascariasis. Ann Saudi Med 1989;9:80-1

13. Sanai FM, Al-Karawi MA. Biliary acsariasis: Report of a complicated case and literature review. Saudi J Gastroenterol 2007;13:25-32.

14. Wani MY, Chechak BA, Reshi F, Pandita S, Rather $\mathrm{MH}$, Sheikh TA, et al . Our experience of biliary ascariasis in children. J Indian Assoc Pediatr Surg 2006;11:129-32. 